\title{
Nursing Leadership Role in Pharmacovigilance Needs Impetus
}

\author{
Biswadeep Das MBBS, MTech, MD", Chayna Sarkar MBBS, MD, DM², Julie Birdie Wahlang MBBS, MD², Saravana Kumar \\ Ramasubbu MBBS, MD ${ }^{1}$ Akash Agnihotri BPharm ${ }^{1}$, Xavier Belsiyal MSc ${ }^{3 *}$ \\ ${ }^{1}$ Department of Pharmacology, All India Institute of Medical Sciences(AIIMS) Rishikesh, Virbhadra Road, Rishikesh-249 203, Uttarakhand, India \\ 2Department of Pharmacology, North Eastern Indira Gandhi Regional Institute of Health and Medical Sciences(NEIGRIHMS), Mawdiangdiang, Shill- \\ ong-793 018, Meghalaya, India \\ ${ }^{3}$ College of Nursing, All India Institute of Medical Sciences(AIIMS) Rishikesh, Virbhadra Road, Rishikesh-249 203, Uttarakhand, India
}

${ }^{\star}$ Corresponding author: Xavier Belsiyal, Assistant Professor, College of Nursing, All India Institute of Medical Sciences(AIIMS), Rishikesh, Virbhadra Road, Rishikesh-249 203, Uttarakhand, India; Tel: +91-135-2462975; Fax: +91-135-2462975; Email: xavier.nur@aiimsrishikesk.edu.in

Received: June 16, 2021; Accepted: June 25, 2021; Published: July 04, 2021

The World Health Organization (WHO) definition of an adverse drug reaction (ADR), is "a noxious and unintended response of a drug, which occurs at a dose normally used in humans for prophylaxis, diagnosis, or therapy" [1]. ADRs are known to wreak serious effects on patients and put a strain on the resources of health services. Past documentation in the medical literature have unraveled that $7-11.2 \%$ of ADRs culminate in hospitalization [2-4]. The financial burden imposed by ADRs with consequent hospitalization was computed to be about Euro 11,357 per hospital bed per year [4]. The financial implication of ADRs in the United States has been put at 30 billion dollar per year [5]. The percentage of ADRs deemed to be avertible is roughly $80 \%$ [4]. Geriatric patients who have been prescribed multiple medications simultaneously due to long-standing afflictions are known to suffer from higher ADR rates [6]. A leading issue in detecting fresh and potential ADRs is under-declaring amidst healthcare providers. A systematic review has disclosed that only $6 \%$ of all ADRs are actually documented [7]. A perpetual issue is under-reporting of ADRs: variously ascribed to: inability or lack of knowledge (in terms of skill) to discern mild or moderate ADRs; fear of being interrogated; vacillation; hard-pressed for time; inefficient reporting processes; ambiguity that the adverse event is relatable to a prescription medication; and the commonly perceived impression that prescribed drugs are primarily safe and are devoid of adverse effects [8]. Nurses are in a distinctive position to oversee the patient's reactions to drugs and, thereupon, where needed, detect and document probable ADRs [9-11]. A recent study has documented that freshly graduated nurses were deficient in terms of possessing the requisite pharmacological knowledge and skills in detecting adverse drug effects [12]. Betterment of one's own capability in ADR declaring is a nurse's responsibility. Two studies $[13,14]$ reported that nurses can commit their efforts quantitatively and qualitatively to ADR reporting and therefore, augment drug-related safety. It has been noted that the nurse's involvement in ADR declaring is still minimal in many nations like Portugal (0.55\%), Sweden (12\%) and Italy (2.6\%) [15-17]. In a recent study from India it was noted that the average knowledge score of the respondents was $43 \%$ on ADR reporting and $16.5 \%$ on ADR burden, indicating that there is still much to be done to educate the nurses regarding ADR reporting [18]. ADR red-flagging and documenting is a mandatory precondition for efficiently and promptly tackling medication-associated issues [19], and ADR monitoring and reporting programmes determine and lessen avertible ADRs, while aiding professionals to combat ADRs skillfully [20].

Nurse-led monitoring and intervention has proven to be a convincing, economical, relatively safe and suitable approach for both service users and professionals, with promise for cost cutting and enhanced quality and safety of care [21]. Many observational studies and randomised controlled trials determined that meticulously planned nurse-led medicines' monitoring tackles issues pertinent to ADRs, promote the quality of prescribing and pain management and direct attention to patients' impressions and reports of adverse events [21-26]. The nurse-managed West Wales Adverse Drug Reaction (WWADR) Profiles were effectively employed by nurses within their usual work schedules [21,23,26,27]. They extend a rigorous and comprehensive check-list for possible medicationinduced damage, the hazard of over-detection being surpassed by the identification of potentially manageable problems of ambiguous aetiology. Novel educational paradigms, like case histories of ADRs [28], can enhance knowledge of ADRs and antecedent hazard factors, like hypersusceptibility to "allergic" reactions, age, polypharmacy, and co-morbid renal, hepatic or cardiac afflictions, which could induce perturbations in drug distribution, metabolism and elimination $[29,30]$. Nurses' collaboration is a crucial modality to track ADRs, as they oversee vital data about patient care, wellbeing, and administration of medications and can identify (red-flag) and document ADRs. A workable modality could be that ADR details (organized into structured checklists) of conceivable ADRs put together by nurses may be set-up prior to scheduled appointments and brainstormed with prescribers and pharmacists [21]. Nurse leadership could steer strategic planning and policy development to revamp practice and enhance quality and safe use of healthcare through utilization of practice guidelines, alteration, elucidation and catering towards motivation for ADR documenting; and providing help and evaluation to nurses to bolster the monitoring and control of ADRs 
[31]. Presently, all professionals, patients, their families, and friends are permitted to relay ADRs to the regulatory authorities. This modality opens up a window of opportunity for nurses to evolve and advance their roles [22]. Apellation of committed nurses to function as "ADR advocates" and connect with a stated prescriber or pharmacist, would boost overseeing and control of ADRs [32]. A number of ADRs could be obviated by improved medication monitoring. The best control of ADRs in healthcare systems necessitates nurses to bear professional authority to determine and detail problems and to alert the prescribers. Since nurses are the professionals most intricately dedicated to handson patient care and put in maximum contact time with patients, they are the ideal professionals to strategically red-flag ADRs [33]. Nurses should be supported to boost their engagement and bear responsibility for customarily determining ADRs [33]. However, to develop nurses for these roles necessitates educational backing and making provision for structured training, as provided by ADR monitoring profiles with standardized protocols $[21,26]$. Such strategies offer leadership possibilities to nurses, juxtaposing them as the pivotal professionals networking amongst patients and their pharmacists, prescribers to assure that ADRs are determined and resolved at the earliest [34,35]. Policy makers and nurse administrators have the occasion to develop, apply and edict structured medication monitoring systems.

\section{References}

1. World Health Organization (1972) International drug monitoring: the role of national centres. Report of a WHO meeting. World Health Organ Tech Rep Ser 488: 1-25.

2. Al Hamid A, Ghaleb M, Aljadhey H, Aslanpour Z (2014) A systematic review of hospitalization resulting from medicine-related problems in adult patients. $\mathrm{Br} \mathrm{J}$ Clin Pharmacol 78: 202-217. [crossref]

3. Kongkaew C, Hann M, Mandal J, Williams SD, Metcalfe D, et al. (2013) Risk factors for hospital admissions associated with adverse drug events. Pharmacotherapy 33: 827-837. [crossref]

4. Lagnaoui R, Moore N, Fach J, Longy-Boursier M, Begaud B (2000) Adverse drug reactions in a department of systemic diseases-oriented internal medicine: prevalence, incidence, direct costs and avoidability. Eur J Clin Pharmacol 56: 181186. [crossref]

5. Sultana J, Cutroneo P, Trifirò G (2013) Clinical and economic burden of adverse drug reactions. J Pharmacol Pharmacother 4.

6. Kongkaew C, Noyce PR, Ashcroft DM (2008) Hospital Admissions Associated with Adverse Drug Reactions: A Systematic Review of Prospective Observational Studies. Ann Pharmacother 42: 1017-1025. [crossref]

7. Hazell L, Shakir SAW (2006) Under-reporting of adverse drug reactions-A systematic review. Drug Saf 29: 385-396. [crossref]

8. Lopez-Gonzalez E, Herdeiro MT, Figueiras A (2009) Determinants of underreporting of adverse drug reactions: a systematic review. Drug Saf 32: 19-31. [crossref]

9. Arnold GJ (1998) Clinical recognition of adverse drug reactions: Obstacles and opportunities for the nursing profession. J Nurs Care Qual 13: 45-55. [crossref]

10. Griffith R (2013) Nurses must report adverse drug reactions. Br J Nurs 22: 484-485.

11. Valente S, Murray L, Fisher D (2007) Nurses improve medication safety with medication allergy and adverse drug reports. J Nurs Care Qual 22: 322-327. [crossref]

12. Lim AG, Honey M (2014) New Zealand newly graduated nurses medication management: results of a survey. Nurse Educ Pract 14: 660-665. [crossref]

13. Hanafi S, Torkamandi H, Hayatshahi A, Gholami K, Shahmirzadi NA, et al. (2014) An educational intervention to improve nurses' knowledge, attitude, and practice toward reporting of adverse drug reactions. Iran J Nurs Midwifery Res 19: 101-116. [crossref]

14. Backstrom M, Ekman E, Mjorndal T (2007) Adverse drug reaction reporting by nurses in Sweden. Eur J Clin Pharmacol 63: 613-618. [crossref]

15. Mendes D, Alves C Batel, Marques F (2014) Nurses' spontaneous reporting of adverse drug reactions: expert review of routine reports. J Nurs Manag 22: 322-230. [crossref]

16. Ulfvarson J, Mejyr S, Bergman U (2007) Nurses are increasingly involved in pharmacovigilance in Sweden. Pharmacoepidemiol Drug Saf 16: 532-537. [crossref]

17. Conforti A, Opri S, D'Incau P, Sottosanti L, Moretti U, Ferrazin F, et al. (2012) Adverse drug reaction reporting by nurses: analysis of Italian pharmacovigilance database. Pharmacoepidemiol Drug Saf 21: 597-602. [crossref]

18. Lohit K, Leena A, Jose M, Pandit AA (2017) Adverse drug reactions reporting among nursing staff and students: a validated questionnaire based knowledge, attitude, and practice study. International Journal of Basic and Clinical Pharmacology 6: 523-527.

19. Desai CK, Iyer G, Panchal J, Shah S, Dikshit RK (2011) An evaluation of knowledge, attitude, and practice of adverse drug reaction reporting among prescribers at a tertiary care hospital. Perspect Clin Res 2: 129-136. [crossref]

20. Arulmani R, Rajendran SD, Suresh B (2008) Adverse drug reaction monitoring in a secondary care hospital in South India. Br J Clin Pharmacol 65: 210-216. [crossref]

21. Jordan S, Gabe-Walters ME, Watkins A, Humphreys I, Newson L, et al. (2015) Nurseled medicines' monitoring for patients with dementia in care homes: a pragmatic cohort stepped wedge cluster randomised trial. PLOS ONE. [crossref]

22. Jordan S, Tunnicliffe C, Sykes A (2002) Minimizing side-effects: the clinical impact of nurse-administered 'side-effect' checklists. J Adv Nurs 37: 155-165. [crossref]

23. Jordan S, Knight J, Pointon D (2004) Monitoring adverse drug reactions: scales, profiles, and checklists. Int Nurs Rev 51: 208-221. [crossref]

24. Gabe ME, Murphy F, Davies GA, Russell IT, Jordan S (2014) Medication monitoring in a nurse-led respiratory outpatient clinic: pragmatic randomised trial of the West Wales Adverse Drug Reaction Profile. PLoS One. [crossref]

25. Jordan S, Hardy B, Coleman M (1999) Medication management: an exploratory study into the role of community mental health nurses. J Adv Nurs 29: 1068-1081. [crossref]

26. Jordan S, Gabe M, Newson L, Snelgrove S, Panes G, Picek A, et al. (2014) Medication monitoring for people with dementia in care homes: the feasibility and clinical impact of nurse-led monitoring. Scientific World Journal. [crossref]

27. Gabe ME, Jordan SE (2014) Development and clinical gains of nurse-led medication monitoring profiles. J Nurs Manag 22: 331-349. [crossref]

28. Jordan S (1997) Teaching pharmacology by case study. Nurse Educ Today. 17: 386393. [crossref]

29. Onder G, Petrovic M, Tangiisuran B, Meinardi MC, Markito-Notenboom WP, et al. (2010) Development and validation of a score to assess risk of adverse drug reactions among in-hospital patients 65 years or older: the GerontoNet ADR risk score. Arch Intern Med 170: 1142-1148. [crossref]

30. Tabali M, Jeschke E, Bockelbrink A, Witt CM, Willich SN, et al. (2009) Educational intervention to improve physician reporting of adverse drug reactions(ADRs) in a primary care setting in complementary and alternative medicine. BMC Public Health 9. [crossref]

31. Gonzalez-Gonzalez C, Lopez-Gonzalez E, Herdeiro MT, Figueiras A (2013) Strategies to improve adverse drug reaction reporting: a critical and systematic review. Drug Saf 36: 317-328. [crossref]

32. Caplan L, Haverhals LM (2012) Barriers and facilitators for preventing adverse drug reactions of long latency: a qualitative study. Int J Risk Saf Med 24: 81-94. [crossref]

33. Mendes D, Alves C, Batel Marques F (2014) Nurses' spontaneous reporting of adverse drug reactions: expert review of routine reports. J Nurs Manag 22: 322-330. [crossref]

34. Vaismoradi M, Bondas T, Salsali M, Jasper M, Turunen H (2014) Facilitating safe care: a qualitative study of Iranian nurse leaders. J Nurs Manag 22: 106-116. [crossref]

35. Vogelsmeier A (2014) Identifying medication order discrepancies during medication reconciliation: perceptions of nursing home leaders and staff. J Nurs Manag 22: 362 372. [crossref]

\section{Citation:}

Biswadeep D, Sarkar C, Birdie Wahlang J, Saravana Kumar R, Akash A, et al. (2021) Nursing Leadership Role in Pharmacovigilance Needs Impetus. Integr J Nurs Med Volume 2(2): 1-2. 